\title{
Aditivos químicos e inoculante bacteriano na ensilagem de cana-de-açúcar: efeitos sobre a fermentação das silagens e o desempenho de garrotes
}

\section{André de Faria Pedroso ${ }^{1}$, Armando de Andrade Rodrigues ${ }^{1}$, Waldomiro Barioni Júnior ${ }^{1}$, Pedro Franklin Barbosa ${ }^{1}$, Flávio Augusto Portela Santos ${ }^{2}$, Luiz Gustavo Nussio²}

\author{
${ }^{1}$ Embrapa Pecuária Sudeste, São Carlos, SP. \\ 2 Departamento de Zootecnia, ESALQ, USP, Piracicaba, SP.
}

RESUMO - Os objetivos neste experimento foram avaliar o desempenho de tourinhos alimentados com rações completas preparadas com silagens de cana-de-açúcar tratadas ou não com aditivos e estudar o efeito dos aditivos sobre a fermentação das silagens. Trinta tourinhos Canchim com peso médio de $312 \mathrm{~kg}$ foram distribuídos em delineamento de blocos casualizados para avaliar três tipos de rações isoproteicas e isoenergéticas (relação volumoso:concentrado de 35:65): ração com silagem sem aditivo (controle); ração com silagem tratada com ureia $(5 \mathrm{~g} / \mathrm{kg}$ de matéria verde, $\mathrm{MV})+$ benzoato de sódio $(0,5 \mathrm{~g} / \mathrm{kg}$ de $\mathrm{MV})$; ração com silagem inoculada com Lactobacillus buchneri $\left(5 \times 10^{4} \mathrm{ufc} / \mathrm{g}\right.$ de $\left.\mathrm{MV}\right)$. As silagens apresentaram $\mathrm{pH}$ adequado à conservação $(<4,2)$, baixos níveis de ácido butírico $(<3 \mathrm{~g} / \mathrm{kg}$ de matéria seca - MS) e elevados níveis de ácido acético ( $>53 \mathrm{~g} / \mathrm{kg}$ de MS). Na silagem tratada com ureia + benzoato e na silagem inoculada, os teores de etanol foram mais baixos em relação à silagem sem aditivo (43; 73 e $92 \mathrm{~g} / \mathrm{kg}$ de $\mathrm{MS}$, respectivamente). A silagem com ureia + benzoato apresentou teores mais elevados de proteína bruta e de nutrientes digestíveis totais em comparação às outras silagens. $\mathrm{O}$ tipo de ração não afeta o ganho de peso vivo (1,75 kg PV/dia) nem a ingestão de MS (10,5 kg MS/dia), mas a conversão alimentar foi melhor nos animais que receberam a ração controle em relação àqueles alimentados com a ração com silagem inoculada (5,71 vs $6,45 \mathrm{~kg}$ MS/kg GPV).

Palavras-chave: ácidos graxos cadeia curta, benzoato, etanol, ganho de peso vivo, L. buchneri, ureia

\section{Chemical additives and a bacterial inoculant on the ensilage of sugarcane: effect on silages fermentation and performance of young bulls}

\begin{abstract}
The objectives of this experiment were to evaluate the performance of young bulls fed total rations prepared with additive treated or untreated sugarcane silages and evaluate the additive effects on silages fermentation. Thirty young Canchim bulls averaging $312 \mathrm{~kg}$ were allotted to a completely randomized experimental design to evaluate three types of isoproteic and isoenergetic rations (roughage:concentrate ratio of 35:65): ration with silage without additive (control), ration with silage treated with urea $(5 \mathrm{~g} / \mathrm{kg}$ of fresh forage - FF $)+$ sodium benzoate $(0.5 \mathrm{~g} / \mathrm{kg} F F)$, ration with silage inoculated with Lactobacillus buchneri $\left(5 \times 10^{4} \mathrm{cfu} / \mathrm{g} \mathrm{FF}\right)$. Silages had $\mathrm{pH}$ adequated to conservation $(<4.2)$, low levels of butyric acid $(<3 \mathrm{~g} / \mathrm{kg}$ in DM) and high levels of acetic acid $(>53 \mathrm{~g} / \mathrm{kg}$ in DM). The silage treated with urea + benzoate and the inoculated silage presented lower ethanol concentration when compared to the untreated silage (43, 73 and $92 \mathrm{~g} / \mathrm{kg}$ in DM, respectively). The silage treated with urea + benzoate had higher crude protein content and total digestible nutrients when compared with other silages. The type of ration affect neither body weight gain (BWG) nor DM intake, but feed conversion was better for animals that received control ration in relation to those fed ration with inoculated silage (5.71 vs $6.45 \mathrm{~kg} \mathrm{DM} / \mathrm{kg} \mathrm{BWG})$
\end{abstract}

Key Words: benzoate, ethanol, L. buchneri, live weight gain, urea, volatile fat acids

\section{Introdução}

A alimentação de bovinos com cana-de-açúcar é tradicional no Brasil, mas a busca por maior eficiência no manejo da alimentação dos rebanhos e dos canaviais tem levado ao aumento do uso da forragem na forma ensilada. Silagens da cana-de-açúcar apresentam, no entanto, intensa fermentação alcoólica e perdas de até $30 \%$ da matéria seca
(MS) durante o armazenamento, o que resulta em grande redução no valor nutritivo da forragem (Pedroso et al., 2005; Freitas et al., 2006).

Diversos produtos têm sido avaliados para o controle da fermentação alcoólica e melhoria do padrão de fermentação durante a ensilagem da cana-de-açúcar. Inoculantes com a bactéria heteroláctica Lactobacillus buchneri, ureia e benzoato de sódio estão entre os aditivos 
mais estudados, mas os resultados com sua aplicação têm sido variáveis (Siqueira et al., 2007; Mari, 2008; Pedroso et al., 2008). Como consequência, diferentes doses de aplicação e a combinação de aditivos têm sido testadas em busca de maior eficiência da técnica (Siqueira et al., 2007). Pedroso et al. (2007) testaram a aplicação conjunta da ureia com benzoato, em doses baixas, e observaram vantagens em relação à aplicação dos aditivos individualmente.

São poucas as informações sobre o valor nutritivo de silagens de cana-de-açúcar produzidas com aditivos. Em pesquisa realizada por Pedroso et al. (2006), o fornecimento de silagens aditivadas com ureia ou benzoato de sódio não afetou o consumo ( $8,7 \mathrm{~kg} \mathrm{MS} / \mathrm{dia})$ e o ganho de peso (1,0 kg/dia) de novilhas holandesas, mas os animais alimentados com silagem produzida com benzoato de sódio apresentaram melhor conversão alimentar (7,6 vs 9,4 kg de MS/ $\mathrm{kg}$ de ganho de peso vivo) em comparação aos animais que receberam silagem sem aditivo. $\mathrm{O}$ arraçoamento com silagem inoculada com $L$. buchneri teve efeito positivo sobre o ganho de peso de novilhas holandesas e de bovinos das raças Nelore e Canchim, como observado também por Schmidt (2006), todavia, em experimento realizado por Mari (2008), não afetou o desempenho de tourinhos Nelore. Mendes et al. (2008) não notaram diferenças no desempenho de cordeiros em crescimento alimentados com silagem inoculada com essa bactéria e de cordeiros alimentados com cana-de-açúcar in natura.

Nesta pesquisa, avaliou-se o desempenho de tourinhos alimentados com rações à base de silagens de cana-deaçúcar produzidas sem aditivo ou com ureia + benzoato de sódio ou com inoculante bacteriano (Lactobacillus buchneri). Concomitantemente, avaliou-se o efeito dos aditivos sobre a produção de etanol, alguns parâmetros de fermentação e a qualidade das silagens.

\section{Material e Métodos}

O experimento foi conduzido na Fazenda Canchim, da Embrapa Pecuária Sudeste, em São Carlos, SP. As silagens para composição das rações experimentais foram produzidas com cana-de-açúcar (IAC86-2480) colhida aos 12 meses de crescimento (segundo corte), com colhedora acoplada ao trator e regulada para tamanho de partículas entre 5 e $10 \mathrm{~mm}$. Foram produzidos três tipos de silagem: silagem sem aditivo; silagem com ureia $(5 \mathrm{~g} / \mathrm{kg}$ de matéria verde - MV) + benzoato de sódio $(0,5 \mathrm{~g} / \mathrm{kg}$ de $\mathrm{MV})$; e silagem inoculada com Lactobacillus buchneri $\left(5 \times 10^{4} \mathrm{ufc} / \mathrm{g}\right.$ de MV).

As silagens foram produzidas em silos de superfície $(1,5 \times 6 \times 20 \mathrm{~m})$ cobertos com lona plástica "dupla face" de $200 \mu$, cada um com aproximadamente $45 \mathrm{t}$ de silagem. Os aditivos foram adicionados e misturados à cana-de-açúcar picada à medida que esta era colocada nos silos. A ureia foi aplicada seca, enquanto o benzoato de sódio e o inoculante foram pulverizados em soluções aquosas. A solução de benzoato de sódio ( $1,7 \mathrm{~kg}$ do produto em $15 \mathrm{~L}$ de água) foi aplicada à taxa de 4,4 L de solução/t de MV. O inoculante bacteriano (cepa NCIMB 40788, Lalsil Cana ${ }^{\circledR}$, Lallemand S.A., Blagnac, França) foi aplicado de acordo com recomendação do fabricante $(2 \mathrm{~g} / \mathrm{L})$ utilizando-se $2,9 \mathrm{~L}$ de solução/t de MV.

Os silos foram abertos 13 meses após a ensilagem e as silagens utilizadas na produção de três tipos de ração (tratamentos): ração com a silagem sem aditivo (controle); ração com a silagem aditivada com ureia + benzoato de sódio; ração com silagem inoculada com L. buchneri. As rações experimentais foram formuladas $(\mathrm{NRC}, 1996)$ para ser isoproteicas ( $15 \%$ de proteína bruta - PB) e isoenergéticas ( $71 \%$ de nutrientes digestíveis totais, NDT), considerando os valores hipotéticos de $55 \%$ de NDT para todas as silagens, $6,5 \%$ e 3,5\% de PB nas silagens com e sem ureia, respectivamente, e visando ganho de peso diário de $1,26 \mathrm{~kg}$ para animais de $312 \mathrm{~kg}$ de peso vivo, PV (Tabela 1).

Para avaliação do desempenho, foram utilizados 30 tourinhos da raça Canchim, com idade média de 19 meses e peso médio inicial de $312 \mathrm{~kg}$, distribuídos em blocos casualizados, de acordo com o PV inicial. Os animais receberam tratamento sanitário, everminação, injeção de vitaminas A, D e E e controle de carrapatos, antes do início do experimento. $\mathrm{O}$ confinamento foi realizado em baias individuais com piso de terra e bebedouros e cochos de alvenaria. O período experimental foi de 88 dias, com 10 dias de adaptação e 78 dias de coleta de dados. O ganho de peso médio diário foi avaliado pesando-se os animais no primeiro dia e ao final do período de coleta de dados, após jejum alimentar de 12 horas.

As rações foram fornecidas na forma de "ração total" (mistura completa), produzidas com o uso de vagão forrageiro provido de balança, sendo a mistura concentrada preparada e pesada previamente. $\mathrm{O}$ alimento fornecido e as sobras foram pesados diariamente, possibilitando o cálculo do consumo diário e o ajuste da quantidade de ração a ser fornecida no dia seguinte, buscando-se o consumo ad libitum das rações (10\% de sobras).

As rações e as sobras foram amostradas uma vez por semana para análise bromatológica. Coletou-se uma porção de aproximadamente $100 \mathrm{~g}$ de cada cocho, para formação de uma amostra composta semanal para cada tratamento (total de dez amostras/tratamento), da qual aproximadamente $300 \mathrm{~g}$ eram colocados em saco de papel e encaminhados para secagem em estufa de ventilação forçada $\left(65^{\circ} \mathrm{C}, 48\right.$ horas $)$. 
Tabela 1 - Composição das rações experimentais

\begin{tabular}{lcc}
\hline Item & Com silagem sem ureia & Com silagem tratada com ureia + benzoato \\
\hline Silagem de cana-de-açúcar & 35,3 & 35,7 \\
Farelo de trigo & 40,5 & 40,5 \\
Refinasil ${ }^{1}$ & 22,2 & 22,2 \\
Calcário $^{\text {Ureia }}$ & 1,3 & 1,3 \\
Suplemento mineral $^{2}$ & 0,4 & -3 \\
\hline
\end{tabular}

${ }^{1}$ Farelo de glúten de milho.

2 Sódio - $350 \mathrm{~g} / \mathrm{kg}$; cobre - $2.100 \mathrm{mg} / \mathrm{kg}$; cobalto - $45 \mathrm{mg} / \mathrm{kg}$; iodo - $190 \mathrm{mg} / \mathrm{kg}$.

Amostras de sobras que se apresentavam excessivamente úmidas, pela ocorrência de chuvas, eram encaminhadas para secagem em bandejas de alumínio. As diferentes silagens também foram amostradas uma vez por semana, antes da mistura com o concentrado no vagão forrageiro, coletando-se porções de aproximadamente $200 \mathrm{~g}$ de cinco pontos da massa de silagem, para formação de uma amostra composta. De cada amostra composta de silagem, aproximadamente $300 \mathrm{~g}$ eram colocados em saco de papel e encaminhados para secagem em estufa e $200 \mathrm{~g}$ eram colocados em saco plástico e congelados $\left(-20^{\circ} \mathrm{C}\right)$ para análise posterior.

As amostras secas em estufa foram moídas em moinho estacionário com peneira de malha de $1 \mathrm{~mm}$ e posteriormente analisadas como segue: matéria seca, matéria mineral (MM), PB, extrato etéreo (EE), N-FDA, Ca e P, segundo AOAC (1990); fibra em detergente ácido (FDA), fibra em detergente neutro (FDN) e lignina (L), de acordo com Van Soest \& Robertson (1985). Os valores de nutrientes digestíveis totais foram calculados segundo Weiss et al. (1992), de acordo com a equação:

$$
\begin{gathered}
\mathrm{NDT}=(0,98 \times \mathrm{CNF})+(0,93 \times \mathrm{PB})+(2,25 \times \mathrm{EE}-1)+0,75 \\
(\mathrm{FDNLP}-\mathrm{L})\left[1-(\mathrm{L} / \mathrm{FDNLP})^{0,667}\right]-7
\end{gathered}
$$

em que: $\mathrm{CNF}$ (carboidratos não-fibrosos) $=100-\mathrm{PB}-\mathrm{MM}$ - EE - FDNLP; FDNLP $($ FDN livre de proteína $)=$ FDN PBFDN e PBFDN = PB ligada ao FDN.

As amostras congeladas de silagem foram utilizadas para determinação de ácidos graxos voláteis (acético, propiônico e butírico), ácido láctico, etanol e pH, no laboratório da Faculdade de Medicina Veterinária e Zootecnia da Universidade de São Paulo, em Pirassununga.
No suco das silagens, extraído com prensa hidráulica, foi medido primeiramente o $\mathrm{pH}$, por meio de um peagâmetro digital, e em seguida realizadas as análises de etanol e dos ácidos graxos voláteis em cromatógrafo a gás, de acordo com Sigma-Aldrich, Co (1998), e do ácido láctico, em sistema de cromatografia líquida de alta performance (HPLC), de acordo com Wilson (1971).

O delineamento experimental para avaliação do desempenho foi em blocos completos casualizados, com cinco blocos, três tratamentos e dez repetições. O delineamento utilizado na comparação dos alimentos e das sobras foi o inteiramente casualizado, com três tratamentos e oito repetições. A análise de variância dos dados de desempenho, de consumo de nutrientes e de composição dos alimentos e das sobras, foi realizada pelo procedimento GLM do SAS (SAS, 2003), adotando-se para comparação das médias dos tratamentos o teste t a 5\% de significância quando o teste $\mathrm{F}$ foi significativo.

\section{Resultados e Discussão}

De acordo com a avaliação da qualidade fermentativa (Tabela 2), as silagens apresentaram $\mathrm{pH}$ adequado à conservação $(<4,2)$, níveis baixos a médios de ácidos propiônico e butírico e elevadas concentrações de ácido acético em comparação a valores descritos na literatura para silagens de cana-de-açúcar (Schmidt et al., 2007; Castro Neto et al., 2008). Os níveis de ácido láctico nas silagens sem aditivo e inoculada com $L$. buchneri foram normais e próximos aos valores obtidos por Freitas et al. (2006) e

\begin{tabular}{|c|c|c|c|c|}
\hline & \multicolumn{3}{|c|}{ Silagem } & \multirow[t]{2}{*}{ Erro-padrão } \\
\hline & Sem aditivo & Ureia + benzoato de sódio & Lactobacillus buchneri & \\
\hline $\mathrm{pH}$ & $3,42 b$ & $3,86 \mathrm{a}$ & $3,41 \mathrm{~b}$ & 0,09 \\
\hline Ácido láctico (g/kg de MS) & $37,5 b$ & $80,6 \mathrm{a}$ & $25,0 \mathrm{c}$ & 6,8 \\
\hline Ácido acético (g/kg de MS) & $67,5 \mathrm{ab}$ & $53,0 \mathrm{~b}$ & $85,1 \mathrm{a}$ & 14,7 \\
\hline Ácido propiônico (g/kg de MS) & $0,04 \mathrm{c}$ & $0,11 \mathrm{~b}$ & $0,24 \mathrm{a}$ & 0,03 \\
\hline
\end{tabular}

Tabela 2 - Características fermentativas das silagens de cana-de-açúcar

abc - Letras diferentes na mesma linha indicam diferença estatística $(\mathrm{P}<0,05)$ pelo teste $\mathrm{t}$ 
Santos et al. (2008), mas o teor do ácido na silagem tratada com ureia + benzoato foi elevado e próximo ao obtido por Pedroso et al. (2007).

O alto teor de MS original da cana-de-açúcar $(290 \mathrm{~g} / \mathrm{kg}$ de MV) e os baixos valores de $\mathrm{pH}$ provavelmente limitaram o desenvolvimento de clostrídia e propionibactéria, reduzindo a produção dos ácidos propiônico e butírico nas silagens (McDonald et al., 1991). As altas concentrações de ácido acético detectadas podem ter sido resultado do tipo de silo utilizado. Silagens produzidas em silos de superfície normalmente apresentam baixa densidade, de forma que, a presença excessiva de oxigênio na massa ensilada pode ter levado ao desenvolvimento prolongado de microorganismos anaeróbios facultativos produtores de ácido acético (Muck, 1988) e ao aumento da concentração do ácido nas silagens.

A aplicação da ureia em combinação com benzoato de sódio promoveu redução de aproximadamente $53 \%$ do teor de etanol (42,7 vs 92,3 g/ $\mathrm{kg}$ de MS), não alterou o teor de ácido acético (53,0 e $67,5 \mathrm{~g} / \mathrm{kg}$ de MS, respectivamente) e aumentou em $26 \%$ o teor de ácido láctico na silagem (80,6 vs $37,5 \mathrm{~g} / \mathrm{kg}$ de MS) em relação à silagem sem tratamento (Tabela 2). Além da menor produção de etanol, a ensilagem da cana-de-açúcar com ureia + benzoato resultou em forragem de melhor qualidade, com teor mais elevado de PB, menor teor de componentes fibrosos (FDN e FDA) e maior conteúdo energético (NDT), quando comparada às silagens sem aditivo e inoculada com $L$. buchneri (Tabela 3 ).

Estes resultados confirmam resultado de experimento anterior em que o uso combinado destes aditivos possibilitou redução significativa (23\%) no teor de etanol e elevação no teor ácido láctico na silagem, em relação à silagem sem tratamento (Pedroso et al., 2007). Ressalta-se que a baixa dose de ureia utilizada permitiu que a silagem atingisse $\mathrm{pH}$ suficientemente baixo $(3,86)$ para adequada conservação da forragem. Os dados permitem inferir que, ao promover redução no desenvolvimento de leveduras, a combinação de aditivos pode ter favorecido o desenvolvimento de bactérias homoláticas, o que explicaria a maior produção de ácido láctico observado nas silagens em ambos os experimentos.

A ureia, quando aplicada à forragem ensilada produz amônia, que tem efeito fungicida, e pode promover o controle de leveduras e reduzir a produção de etanol em silagens de cana-de-açúcar (Pedroso et al., 2008). Níveis mais elevados deste aditivo (10 e $15 \mathrm{~g} / \mathrm{kg}$ de MV), no entanto, podem resultar em $\mathrm{pH}$ final excessivamente alto nas silagens, devido ao efeito tamponante da amônia, e em perdas gasosas elevadas durante o processo de conservação (Evangelista et al., 2006; Pedroso et al., 2007). O benzoato de sódio, por sua vez, dissocia-se durante a ensilagem liberando ácido benzóico, que tem ação inibidora sobre leveduras e mofos (Woolford, 1975). Em alguns trabalhos, a aplicação deste aditivo isoladamente, possibilitou redução na produção de etanol e nas perdas de MS, com aumento na digestibilidade e na estabilidade aeróbia em silagens de cana-de-açúcar (Siqueira et al., 2007; Pedroso et al., 2008). O uso combinado dos dois aditivos, em doses baixas, permite aproveitar os benefícios da utilização da ureia na ensilagem da cana-deaçúcar, como a elevação do teor de proteína da forragem e maior segurança na utilização do produto, sem os inconvenientes observados quando a ureia é utilizada em doses altas.

A silagem inoculada com $L$. buchneri apresentou teor de etanol $21 \%$ inferior em relação à silagem não tratada (72,5 vs 92,3 g/kg de MS) (Tabela 2). O teor de ácido acético não foi alterado pelo uso do inoculante em relação à silagem sem tratamento, mas foi superior ao da silagem tratada com ureia e benzoato $(85,1 ; 67,5$ e 53,0 , respectivamente). A concentração de ácido láctico na silagem inoculada foi a menor entre as silagens $(25,0 \mathrm{~g} / \mathrm{kg}$ de MS), correspondendo a uma redução de 33\% em relação à silagem sem aditivos. A redução no teor de ácido láctico na silagem explica-se pelo fato de que bactérias heterofermentativas da espécie L. buchneri utilizam este ácido para crescimento, produzindo como resíduo metabólico o ácido acético, e em menores quantidades, 1,2 propanodiol, ácido propiônico e dióxido de carbono

Tabela 3 - Composição das silagens e rações experimentais (g/kg de MS)

\begin{tabular}{|c|c|c|c|c|c|c|c|c|}
\hline & \multicolumn{3}{|c|}{ Silagem } & \multirow[t]{2}{*}{ Erro-padrão } & \multicolumn{3}{|c|}{ Ração } & \multirow[t]{2}{*}{ Erro-padrão } \\
\hline & $\begin{array}{c}\mathrm{S} 1 \\
\text { (sem aditivo) }\end{array}$ & $\begin{array}{c}\text { S2 } \\
(\text { com ureia }+ \\
\text { benzoato de sódio })\end{array}$ & $\begin{array}{c}\mathrm{S} 3 \\
\text { (com Lactobacillus } \\
\text { buchneri) }\end{array}$ & & $\begin{array}{c}\text { Com } \\
\text { silagem S1 }\end{array}$ & $\begin{array}{c}\text { Com } \\
\text { silagem S2 }\end{array}$ & $\begin{array}{c}\text { Com } \\
\text { silagem S3 }\end{array}$ & \\
\hline Matéria seca (g/kg de MV) & $257 \mathrm{~b}$ & $285 a$ & $259 b$ & 5,5 & $475 \mathrm{C}$ & $516 \mathrm{~A}$ & 498B & 18,2 \\
\hline Proteína bruta & $34,5 b$ & $79,2 \mathrm{a}$ & $35,1 b$ & 2,6 & $134 \mathrm{~B}$ & $141 \mathrm{~A}$ & $137 \mathrm{AB}$ & 6,6 \\
\hline Fibra em detergente neutro & $699 a$ & $632 b$ & $707 a$ & 30,2 & 480 & 458 & 480 & 39,3 \\
\hline Fibra em detergente ácido & $451 \mathrm{a}$ & $404 b$ & $469 a$ & 30,3 & 224 & 204 & 221 & 23,5 \\
\hline Nutrientes digestíveis totais & $553 b$ & $586 a$ & $554 b$ & 20,2 & 663 & 672 & 657 & 23,1 \\
\hline
\end{tabular}

Letras minúsculas diferentes na linha indicam diferença estatística $(\mathrm{P}<0,05)$ pelo teste $\mathrm{t}$ para componentes das silagem.

Letras maiúsculas diferentes na linha indicam diferença estatística $(\mathrm{P}<0,05)$ pelo teste t para componentes das rações. 
(Oude et al., 2001). Apesar da redução na fermentação alcoólica, a inoculação não melhorou a composição da silagem em relação à silagem sem aditivos, tendo em vista os teores de proteína, componentes da fibra e NDT (Tabela 3 ).

Os resultados da inoculação de silagens de cana-deaçúcar com L. buchneri têm sido variáveis. Em alguns trabalhos, foram obtidos resultados positivos, como redução na contagem de leveduras e na produção de etanol (Mendes et al., 2008; Pedroso et al., 2008), mas em algumas pesquisas os mesmos efeitos não foram observados (Freitas et al., 2006; Santos et al., 2008). Segundo Schmidt (2008), a variabilidade no padrão de resposta à aplicação deste inoculante parece ser superior à de outros aditivos, possivelmente, porque muitos fatores podem afetar o desenvolvimento dos microrganismos.

De forma geral, a redução na fermentação alcoólica e as alterações na composição bromatológica nas silagens tratadas com os aditivos causaram pequena alteração na composição das rações experimentais, em relação à ração produzida com a silagem sem aditivo (Tabela 3). Houve pequeno aumento no teor de MS das rações produzidas com as duas silagens aditivadas e de PB na ração produzida com a silagem tratada com ureia + benzoato, em relação ao controle.

A similaridade na composição básica das rações era esperada, por ter sido considerado no balanceamento maior teor de proteína para a silagem tratada com ureia + benzoato $(6,5 \%)$ e pela alta proporção de alimentos concentrados. Desta forma, diferenças de desempenho poderiam ocorrer se diferenças nos produtos de fermentação das silagens como teores de etanol e de ácidos graxos de cadeia curta afetassem a aceitabilidade e o consumo das rações. No entanto, o ganho de peso vivo (GPV) e a ingestão de MS não foram influenciados pelo tipo de ração (Tabela 4).

Os garrotes apresentaram GPV diário médio de $1,75 \mathrm{~kg}$ e consumiram em média $10,5 \mathrm{~kg}$ de MS de ração por dia, equivalente a 2,8\% do PV. A conversão alimentar, porém, foi melhor para os animais alimentados com a ração controle, em relação aos animais alimentados com a ração preparada com a silagem inoculada (5,71 vs $6,45 \mathrm{~kg} \mathrm{MS} / \mathrm{kg} \mathrm{GPV})$. A conversão alimentar dos animais alimentados com a silagem tratada com ureia + benzoato foi intermediária aos dois outros tratamentos (6,15 kg MS/kg GPV).

A melhor conversão alimentar apresentada pelos animais alimentados com a silagem sem tratamento, em relação aos animais alimentados com a silagem inoculada, apesar de não ter havido diferença significativa no consumo de MS, pode ser explicada analisando-se a quantidade de nutrientes fornecidos, a quantidade de nutrientes nas sobras e a ingestão de nutrientes calculada para os animais (Tabela 4). Apesar de o fornecimento de NDT ter sido igual para os dois grupos de animais (aproximadamente $8 \mathrm{~kg} /$ animal/dia), a quantidade de PB fornecida foi maior para os animais alimentados com a ração controle ( 1,65 vs $1,50 \mathrm{~kg} / \mathrm{animal} / \mathrm{dia}$ ). Além disso, as sobras deixadas pelos animais alimentados com a ração controle apresentaram menor quantidade de PB (1,41 vs $1,25 \mathrm{~kg} /$ animal/dia) e NDT (1,28 vs $1,82 \mathrm{~kg} / \mathrm{animal} / \mathrm{dia})$, o que resultou em maior ingestão de PB (1,41 vs $1,25 \mathrm{~kg} /$ animal/dia)s e NDT $(6,88$ vs $6,12 \mathrm{~kg} / \mathrm{animal} / \mathrm{dia}$ ) pelos animais deste tratamento, em relação aos alimentados com a silagem inoculada.

O desempenho dos animais foi semelhante ao obtido por Pereira et al (2007), que obteve ingestão média de $10,7 \mathrm{~kg}$ MS/dia e GPV médio de 1,6 kg/dia, com tourinhos da

Tabela 4 - Consumo de nutrientes e índices de desempenho de garrotes da raça Canchim alimentados com rações à base de silagens de cana-de-açúcar aditivadas

\begin{tabular}{lccc}
\hline Item & \multicolumn{2}{c}{ Silagem utilizada na ração } & Erro-padrão \\
\cline { 2 - 4 } & Sem aditivo & Com ureia + benzoato de sódio & Com Lactobacillus buchneri \\
\hline Peso vivo inicial $(\mathrm{kg})$ & 309 & 316 & 311 \\
Peso vivo final (kg) & 454 & 454 & 436 \\
Ganho de peso vivo (kg/dia) & 1,87 & 1,76 & 1,61 \\
Ingestão de MS (kg/d) & 10,5 & 10,7 & 10,2 \\
Conversão (kg MS/kg GPV) & $5,71 \mathrm{~b}$ & $6,15 \mathrm{ab}$ & $6,45 \mathrm{a}$ \\
Fornecido (kg/animal/dia) & & & 0,3 \\
Proteína bruta & $1.65 \mathrm{~b}$ & $1.78 \mathrm{a}$ & 0,73 \\
Nutrientes digestíveis totais & 8.16 & 8.52 & $1.50 \mathrm{c}$ \\
Sobra (kg/animal/dia) & & & 7.94 \\
Proteína bruta & $0.23 \mathrm{c}$ & $0.29 \mathrm{a}$ & 0,13 \\
Nutrientes digestíveis totais & $1.28 \mathrm{c}$ & $1.59 \mathrm{~b}$ & 0,66 \\
Ingerido (kg/animal/dia) & & & $0.25 \mathrm{~b}$ \\
Proteína bruta & $1.41 \mathrm{a}$ & $1.50 \mathrm{a}$ & $1.82 \mathrm{a}$ \\
Nutrientes digestíveis totais & $6.88 \mathrm{a}$ & $6.92 \mathrm{a}$ & 0,02 \\
\hline
\end{tabular}

Letras minúsculas diferentes na linha indicam diferença estatística $(\mathrm{P}<0,05)$ pelo teste $\mathrm{t}$. 
raça Canchim (318 kg de PV) alimentados com rações produzidas com $30 \%$ de silagem de cana-de-açúcar inoculada com L. buchneri.

Mari (2008), em outro experimento onde se utilizou alta proporção de alimentos concentrados na dieta, também não obteve diferença no ganho de peso e consumo de MS de tourinhos alimentados com rações produzidas com $40 \%$ de silagem de cana-de-açúcar inoculada com L. buchneri, em comparação àqueles alimentados com silagem de cana sem aditivo, apesar de a inoculação ter melhorado a composição bromatológica e a digestibilidade da silagem.

Rações com silagens inoculadas com L. buchneri resultaram em melhoria no desempenho dos animais em avaliações em que foram utilizadas rações contendo maior proporção de alimentos volumosos. Pedroso et al. (2006) reportaram ganho de peso superior em novilhas holandesas (1,24 vs $0,94 \mathrm{~kg} / \mathrm{dia})$ e Schmidt (2006) observou aumento no ganho de peso ( 1,03 vs $0,82 \mathrm{~kg} /$ dia) e melhor conversão alimentar ( 8,7 vs $9,7 \mathrm{~kg}$ de MS/kg de PV) em tourinhos Nelore e Canchim, quando os animais foram alimentados com rações que continham aproximadamente $55 \%$ de silagem inoculada com L. buchneri, em relação aos animais alimentados com silagem sem aditivos. Possivelmente, nos referidos trabalhos, a utilização de menor proporção de alimentos concentrados nas rações aumentou o efeito da qualidade do volumoso nas dietas, permitindo a obtenção de diferenças no desempenho dos animais.

Deve-se salientar que, apesar da ingestão de ácido acético pelos animais que receberam a silagem inoculada com L. buchneri ter sido de aproximadamente $280 \mathrm{~g} / \mathrm{dia}$, a ingestão de MS da ração não foi prejudicada, corroborando informações de que o conteúdo deste ácido per se não afeta o consumo de silagens por bovinos, quando os demais aspectos da silagem indicam boa conservação (Taylor et al., 2002).

O ganho de peso médio geral dos animais foi $39 \%$ superior ao previsto no balanceamento ( $1,75 \mathrm{vs} 1,26 \mathrm{~kg} / \mathrm{d})$. Pedroso et al (2006) também obtiveram ganho de peso $28 \%$ acima do esperado em animais alimentados com silagem de cana-de-açúcar, tendo sido levantada a hipótese de que o valor nutritivo de silagens de cana-de-açúcar tem sido subestimado pelo fato de não se considerar o valor energético de componentes voláteis, como ácidos graxos de cadeia curta, etanol e outros alcoóis, que se perdem durante o processamento normal das silagens para análise bromatológica e cálculo do NDT (Pedroso et al., 2004).

\section{Conclusões}

Efeitos positivos da utilização de aditivos na fermentação de silagens de cana-de-açúcar podem não se traduzir em melhoria no ganho de peso e consumo de MS de bovinos de corte confinados se as rações forem preparadas com alta proporção de concentrado. Neste caso, o benefício do uso de aditivos deve ser avaliado em função da provável redução no custo da forragem, decorrente da diminuição de perdas fermentativas durante a ensilagem e da menor quantidade de alimentos concentrados na dieta quando as rações são balanceadas com base na composição real das silagens.

\section{Agradecimentos}

À Bellman Nutrição Animal pela doação do sal mineralizado usado no arraçoamento dos animais.

\section{Referências}

ASSOCIATION OF OFFICIAL ANALYTICAL CHEMISTIS. Official methods of analysis. 15.ed. Arlington, 1990. v.1, $1117 \mathrm{p}$.

CASTRO NETO, A.G.; MOLINA, L.R.; GONÇALVES, L.C. et al Parâmetros de fermentação de silagens de cana-de-açúcar submetidas a diferentes tratamentos. Arquivo Brasileiro de Medicina Veterinária e Zootecnia, v.60, p.1150-1156, 2008. EVANGELISTA, A.R.; LOPES, J.; SALVADOR, F.M. et al. Silagem de cana-de-açúcar acrescida de ureia e produtos sequestrantes de umidade. In: REUNIÃO DA SOCIEDADE BRASILEIRA DE ZOOTECNIA, 43., 2006, João Pessoa. Anais... João Pessoa: SBZ, 2006. (CD-ROM).

FREITAS, A.W.P.; PEREIRA, J.C.; ROCHA, F.C. et al. Avaliação da qualidade nutricional da silagem de cana-de-açúcar com aditivos microbianos e enriquecida com resíduo da colheita de soja. Revista Brasileira de Zootecnia, v.35, p.38-47, 2006.

MARI, L.J. Desempenho de bovinos de corte alimentados com rações contendo cana-de-açúcar (Saccharum officinarum L.) fresca ou ensilada e o padrão de fermentação e a estabilidade aeróbia das silagens aditivadas. 2008. 315f. Tese (Doutorado em Agronomia) Escola Superior de Agricultura "Luiz de Queiroz", Universidade de São Paulo, Piracicaba.

McDOnAld, P.; HENDERSON, A.R.; HERON, S.J.E. The biochemistry of silage. 2.ed. Marlow: Chalcomb Publications, 1991. 340p.

MENDES, C.Q.; SUSIN, I.; PIRES, A.V. et al. Desempenho, parâmetros da carcaça e comportamento ingestivo de cordeiros alimentados com cana-de-açúcar ensilada ou in natura. Arquivo Brasileiro de Medicina Veterinária e Zootecnia, v.60, n.3, p.733-740, 2008.

MUCK, R.E. Factors influencing silage quality and their implications for management. Journal of Dairy Science, v.71, p.2992-3002, 1988.

NATIONAL RESEARCH COUNCIL - NRC. Nutrient requirements of beef cattle. 7.ed. Washington, D.C.: National Academy Press, 1996. $381 \mathrm{p}$.

OUDE EELFERINK, S.J.H.W.; KROONEMAN, J.; GOTTSCHAL., J.C. et al. Anaerobic conversion of lactic acid to acetic acid and 1,2-propanediol by Lactobacillus buchneri. Applied and Environmental Microbiology, v.67, p.125-132, 2001

PEDROSO, A.F.; SCHMIDT, P.; NUSSIO, L.G. Silagem de cana-deaçúcar no confinamento de bovinos. In: SIMPÓSIO SOBRE BOVINOCUlTURA DE CORTE, 5., 2004, Piracicaba. Anais.. Piracicaba: FEALQ, 2004. p.246-259. 
PEDROSO, A.F.; NUSSIO, LG.; PAZIANI, S.F. et al. Fermentation and epiphytic microflora dynamics in sugar cane silage. Scientia Agricola, v.62, p.427-432, 2005.

PEDROSO, A.F.; NUSSIO, L.G.; BARIONI JR., W. et al. Performance of Holstein heifers fed sugarcane silages treated with urea, sodium benzoate or Lactobacillus buchneri. Pesquisa Agropecuária Brasileira, v.41, p.649-654, 2006.

PEDROSO, A.F.; RODRIGUES, A.A.; BARIONI JUNIOR, W. et al. Características da fermentação e perdas em silagens de cana-deaçúcar tratadas com aditivos químicos ou inoculantes bacteriano. In: REUNIÃO ANUAL DA SOCIEDADE BRASILEIRA DE ZOOTECNIA, 44., 2007, Jaboticabal. Anais... Jaboticabal: SBZ: UNESP, 2007. (CD-ROM).

PEDROSO, A.F.; NUSSIO, L.G.; LOURES, D.R.S. et al. Fermentation, losses, and aerobic stability of sugarcane silages treated with chemical and bacterial additives. Scientia Agricola, v.65, p.567-691, 2008.

PEREIRA, E.; SANTOS, F.; BITTAR, C. et al. Substituição do milho por farelo de trigo ou farelo de glúten de milho na ração de bovinos de corte em terminação. Acta Scientiarum.Animal Sciences, v.29, p.49-55, 2007.

SANTOS, M.C.; NUSSIO, L.G.; MOURÃO, G.B. et al. Influência da utilização de aditivos químicos no perfil da fermentação, no valor nutritivo e nas perdas de silagens de cana-de-açúcar. Revista Brasileira de Zootecnia, v.37, p.1555-1563, 2008.

SCHMIDT, P. Perdas fermentativas na ensilagem, parâmetros digestivos e desempenho de bovinos de corte alimentados com rações contendo silagens de cana-de-açúcar. 2006. 229f. Tese (Doutorado em Agronomia) - Escola Superior de Agricultura Luiz de Queiroz/Universidade de São Paulo, Piracicaba.

SCHMIDT, P.; MARI, L.J.; NUSSIO, L.G. et al. Aditivos químicos e biológicos na ensilagem de cana-de-açúcar. 1. Composição química das silagens, ingestão, digestibilidade e comportamento ingestivo. Revista Brasileira de Zootecnia, v.36, n.5, p.16661675, 2007 (supl.).

SCHMIDT, P. Aditivos químicos e biológicos no tratamento da canade-açúcar para alimentação de bovinos. In: JOBIM, C.C.; CECATO, U.; CANTO, M.W. et al. (Eds.) Produção e utilização de forragens conservadas. Maringá: UEM, 2008. p.117-152.

SIGMA-ALDRICH Co. Analyzing fatty acids by packed column gas chromatofraphy. Bellefonte: SUPELCO, 1998. 12p (Bulletin, 856B).

SIQUEIRA, G.R.; REIS, R.A.; SCHOCKEN-ITURRINO, R.P. et al. Perdas de silagens de cana-de-açúcar tratadas com aditivos químicos e bacterianos. Revista Brasileira de Zootecnia, v.36, n.6, p.2000-2009, 2007.

STATISTICAL ANALYSES SYSTEM - SAS. System for Microsoft Windows. Release 9.1. Cary: SAS Institute, 2003. (CD-ROM).

TAYLOR, C.C.; RANJIT, N.J.; MILLS, J.A. et al. The effect of treating whole-plant barley with Lactobacillus buchneri 40788 on silage fermentation, aerobic stability, and nutritive value for dairy cows. Journal of Dairy Science, v.85, p.1793-1800, 2002.

Van SOEST, P.J.; ROBERTSON, J.B. Analysis of forages and fibrous foods. Ithaca: Cornell University, 1985. 202p

WEISS, W.P.; CONRAD, H.R.; ST. PIERRE, N.R. A theoreticallybased model for predicting total digestible nutrient values of forages and concentrates. Animal Feed Science and Technology, v.39, p.95-110, 1992.

WILSON, R.K.A. A rapid accurate method for measuring volatile fatty acids and lactic acid in silage. Dublin, Ireland: Agricultural Institute, Dunsinea Research Centre, 1971. 7p. (Research Report).

WOOLFORD, M.K. Microbial screening of food preservatives, cold sterilants and specific antimicrobial agents as potential silage additives. Journal of Science of Food and Agriculture, v.26, p.229-237, 1975. 